\title{
A Cross Sectional Study for Assessment of Menopausal Symptoms and Coping Strategies among the Women of 40-60 Years Age Group Attending Outpatient Clinic of Gynaecology
}

\author{
Anil K Agarwal, Nirmala Kiron* Rajesh Gupta, Aditi Sengar
}

Anil K Agarwal, Nirmala Kiron* Rajesh Gupta, Aditi Sengaír

Department of Community Medicine, G. R. Medical College, Gwalior, Madhya Pradesh, INDIA.

\section{Correspondence}

Dr. Nirmal Kiran

Department of Community Medicine, G. R. Medical College, Gwalior-474009, Madhya Pradesh, INDIA.

Phone no: 9871365095

Email: dr.nirmala.kiron@gmail.com

\section{History}

- Submission Date: 09-06-2018;

- Revised Date: 09-09-2018;

- Accepted Date: 24-10-2018;

DOI : 10.5530/ijmedph.2019.1.4

\section{Article Available online}

http://www.ijmedph.org/v9/i1

\section{Copyright}

(C) 2019 Phcog.Net. This is an openaccess article distributed under the terms of the Creative Commons Attribution 4.0 International license.

\begin{abstract}
Background: Menopause is one of the most significant events in a woman's life and brings in a number of physiological changes that affect the life of a woman permanently and can be influenced by various socio-demographic factors and coping activities. Objectives: To determine the commonly reported menopausal symptoms among women of 40 to 60 years and to correlate identified menopausal problems with coping strategies found in participants. Methods: By Modified Menopause Rating Scale [MRS] questionnaire, 150 menopausal women aged 40-60 years were interview to document of 12 symptoms (using divided into somatic, psychological and urogenital domain) commonly associated with menopause The women were asked whether or not they had experienced the 12 menopausal symptoms shown in the MRS in the previous one month (30 days) and grading was made to "present" or "absent" of symptoms. Results: Among those women studied, 34 (22.7\%) were premenopausal, 59 $(39.3 \%)$ perimenopausal and $59(38.0 \%)$ postmenopausal and the mean age of menopause was 49.8 years $( \pm 4.9)$ range 43 - 57 years. The most prevalent symptoms reported were joint and muscular discomfort (70.6\%); physical and mental exhaustion (61.3\%); and sleeping problems $(59.3 \%)$. Followed by symptoms of anxiety $(48.6 \%)$; irritability $(45.3 \%)$ hot flushes and sweating (38.6; dryness of vagina (37.9\%); depressive mood (38.0\%). Other complaints noted were incontinence/Frequency of urine (27.3 and heart discomfort (23.3\%). Perimenopausal women $(47.2 \%)$ experienced higher prevalence of somatic and psychological symptoms compared to premenopausal $(n=15.6)$ and postmenopausal $(37.2 \%)$ women. However urogenital symptoms found more in postmenopausal group of women. There is a strong significant favourable association between the menopausal symptoms and coping strategies like exercise, yoga adopted by the menopausal women. Conclusion: Symptoms have variable onset in relation to menopause. Some women experience symptoms earlier during perimenopause while some experience them at a later time. The application of various coping methods, including the establishment of social support networks, is warranted to enhance postmenopausal women's behaviors in different aspects.

Key words: Menopausal Rating Scale (MRS), Menopausal symptoms, Middle age women, Coping strategies.
\end{abstract}

\section{INTRODUCTION}

The word menopause simply refers to the permanent end of menstruation. Menopause has been considered a major transition point in women's reproductive and emotional life. Menopause is not a disease but a natural transition in a women's life that results from a decrease in the ovarian production of sex hormones such as Estrogen, Progesterone and Testosterone. By loss of reproductive potential and transition into later life she may become a victim of both physically and psychologically problems. Physical complaints in order of frequency are as follows: hot flashes, night sweats or chills, disrupted sleep, vaginal dryness, loss of libido, loss of energy, mood swings, increased irritability, loss of skin tone and urinary leakage. Psychological complaints include loss of confidence, depressed mood, irritability, forgetfulness and difficulty in concentrating, panic attacks and anxiety. ${ }^{1,2}$ The symptoms of depression and menopause are similar. ${ }^{3}$ Some of menopausal symptoms experienced by these women can be severe enough to affect their normal daily activities. Unfortunately majority of these women are not aware of the changes brought about by menopause. $^{4-7}$ These symptoms are directly resulted from depletion of estrogen level as women approaches menopausal stage and some of these women begin to experiences these menopausal symptoms early in the perimenopausal phase. The common climacteric symptoms experienced by them can be group into: vasomotor, physical, psychological or sexual complaints. In coping with stress, people tend to use one of the three main coping strategies: either appraisal focused, problem focused or emotion focused coping.

Cite this article : Agarwal AK, Kiron N, Gupta R, Sengar A. A Cross Sectional Study for Assessment of Menopausal Symptoms and Coping Strategies among the Women of 40-60 Years Age Group Attending Outpatient Clinic of Gynaecology. Int J Med Public Health. 2019;9(1):13-9. 
Various coping strategies are adopted by post menopausal women. Given that quite active physical exercise, awareness on diet and weight with creative activities had been found to help with menopause, this observation is no real surprise. Ultimately, it depends on what is going on for each woman and this can vary over time anyway. If you're feeling really tired all the time, restorative poses of coping activity may be best for that period. ${ }^{8}$

Various tools or instruments have been designed to measure and assess symptoms during the menopausal transition; among them is Menopause Rating Scale (MRS) which is designed to assess menopause specific health related Quantity of Life (QoL) to measure the severity of age/ menopause-related complaints by rating a profile of symptoms. ${ }^{9}$

Though studies have been conducted worldwide to explore problems of menopausal women, there hasn't been a huge effort shown in this regards by Indian researchers. In India menopause is considered as a normal phenomenon. Women themselves may not seek medical help for problems associated with ageing. Majority of the women do not understand the complication and issues associated with menopause. In this context the present study tries to examine the menopausal symptoms by modified MRS of middle to old age women and explore status of coping strategies adopted by them for relieving menopausal symptoms.

\section{METHODS AND MATERIALS}

The present study was based on an empirical study carried out in Gwalior city of Madhya Pradesh India among the women of 40-60 years.

\section{Subjects and Setting}

This is a cross-sectional study conducted from the month of July 2017 to February 2018. This study was approved by Ethical Committee of G. R. Medical College Gwalior. The interview was carried out among middle age women ages of 40 to 60 years who visited the Obstetrics and Gynaecology Department of J. A. Group of Hospital Gwalior. The inclusion criteria consisted of women between the ages of 40 to 60 years who had given consent to participate in this study. Pregnant and breastfeeding women, women with associated co-morbidities such as hypertension, diabetes mellitus or heart disease or who were undergoing treatment for cancer were excluded from the study. Menopausal status was classified according to STRAW (Stages of Reproductive Aging Workshop) classification which divided menopause staging into: Postmenopausal; no menstrual bleeding in the previous/last 12 months. Perimenopause; had menstruation in the previous/last 2-12 months but had increasing irregularity of menses without skipping periods and Premenopause; minor changes in cycle length particularly decreasing length of the cycle. ${ }^{10,11}$

\section{Instrument and data collection}

In the study, the questionnaire includes socio-demographic informations, Menopause Rating Scale and coping strategies with menopause symptoms questionnaire were used. The questionnaire includes sociodemographic characteristics of the participants such as age, education, employment status, marital status, average household income and BMI (Body mass index=weight divided by height square in meter) etc.

Menopause Rating Scale (MRS) questionnaire was developed by Heinemann et al..$^{10}$ and is composed of 11 items related to menopausal complaints were used as a basis for assessing menopausal symptoms in this study, this is a self-administered instrument which has been widely used and validated and have been used in many clinical and epidemiological studies and in research on the etiology of menopausal symptoms to assess the menopausal symptoms. The original MRS is composed of 11 items but after pilot study and for more validation we had changed items in to uro-genital section for making more specific of symptoms and formed into 12 items MRS and was divided into three subscales:
(a)Somatic-hot flushes, heart discomfort/palpitation, sleeping problems and muscle and joint problems; (b) Psychological-depressive mood, irritability, anxiety and physical and mental exhaustion and (c) UrogenitalPain/Burning sensation in vulva/vagina, Burning Micturition, Incontinence/Frequency of urine and dryness of the vagina. Each of the twelve symptoms contained a scoring scale from " 0 " (no complaints) to " 1 " (present complaint). Therefore, this study determined the prevalence of menopausal symptoms and not the severity of the symptoms.

The "coping with menopause symptoms" questionnaire questions self-, medical and alternative coping methods used by women to cope with the symptoms of menopause. This questionnaire was prepared by the researchers through a literature review.

All women were interviewed in Hindi language. Face-to-face interview were done on all the women by female P.G. (MD) students with 1 supportive female staff viz. Lady Health Visitor Interviewers were ready to themselves to make sure right answer was given by participants and explanations can be given if the women were in doubt or unclear about the questions asked. Before the women were asked questions were asked, they were assured that the information they submitted would be confidential. Socio-economic status of the study participants was classified according to Agarwal classification based on the latest AICPI of India and per capita income. ${ }^{12}$

\section{Statistical Analysis}

The study subjects were classified into pre-menopausal, perimenopausal and post menopausal group. Further analysis of different variables was done for all three groups separately. The analysis was done using Epi info version7, Epical and Ms Excel software. The data was analyzed and expressed in form of mean, Standard Deviation (SD). Analysis of variance (Fisher exact test), Univariate odds ratio was calculated as an estimate for relative risk (OR). Chi square and ' $t$ ' test (difference of means) were applied to determine the $\mathrm{p}$ value and statistical significance. $P$ value $<0.05$ was considered statistically significant.

\section{RESULTS}

One hundred and fifty women completed the study; those were selected by the purpose of investigator with convenient non random sampling. The mean age of respondents in this study was $50.83 \pm 6.30$ years. The mean age at menopause was $49.8 \pm 4.89$ years with median of 50.6 years. Among these women, 34 (22.7\%) were premenopausal, 59 (39.3\%) perimenopausal and $59(38.0 \%)$ postmenopausal. Majority of women $48(32.0 \%)$ having menopause belongs to the age group in between 51-55 years. (Table 1 ).

By studying socio demographic variables of participants most of them $124(82.7 \%)$ belongs to The Hindu religion, 116 (77.3\%) women were married. Majority 77 (51.3\%) of the participants were housewives and $110(73.3 \%)$ had secondary or less years of schooling. Most of the participants $116(77.3 \%)$ belongs to middle class had a monthly income in between 5000-12000 per capita. Majority of women $103(68.7 \%)$ have high BMI $(>25)$ then the normal $(18.5$ to $<25)$. After analysis of variance of these demographic variables and mean age of menopause we found that mean age of menopause increased by the higher educational status $(p=0.008)$ and women belongs to upper middle and upper class also have higher mean age of menopause symptoms $\operatorname{started}(p=0.024)$ but mean age of menopause decreased significantly in obese women $(p=0.001)$. There was not found any significant difference in mean age of menopause due to other conditions like marital status, religion and due to occupational condition $(P>0.05)$ (Table 2$)$

Table 3 shows the frequency of menopausal symptoms as assessed by the modified MRS according to most frequent complaints. The three most prevalent menopausal symptoms for all women $(n=150)$ were: 
Agarwal, et al.: A Study of Assessment Menopausal Symptoms and Coping Strategies Among Middle Age Women of North Central India

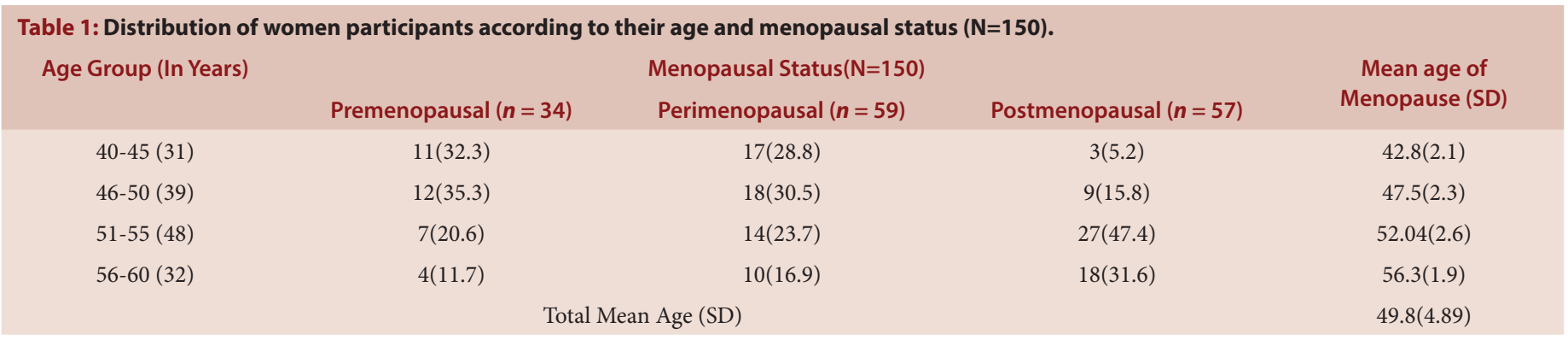

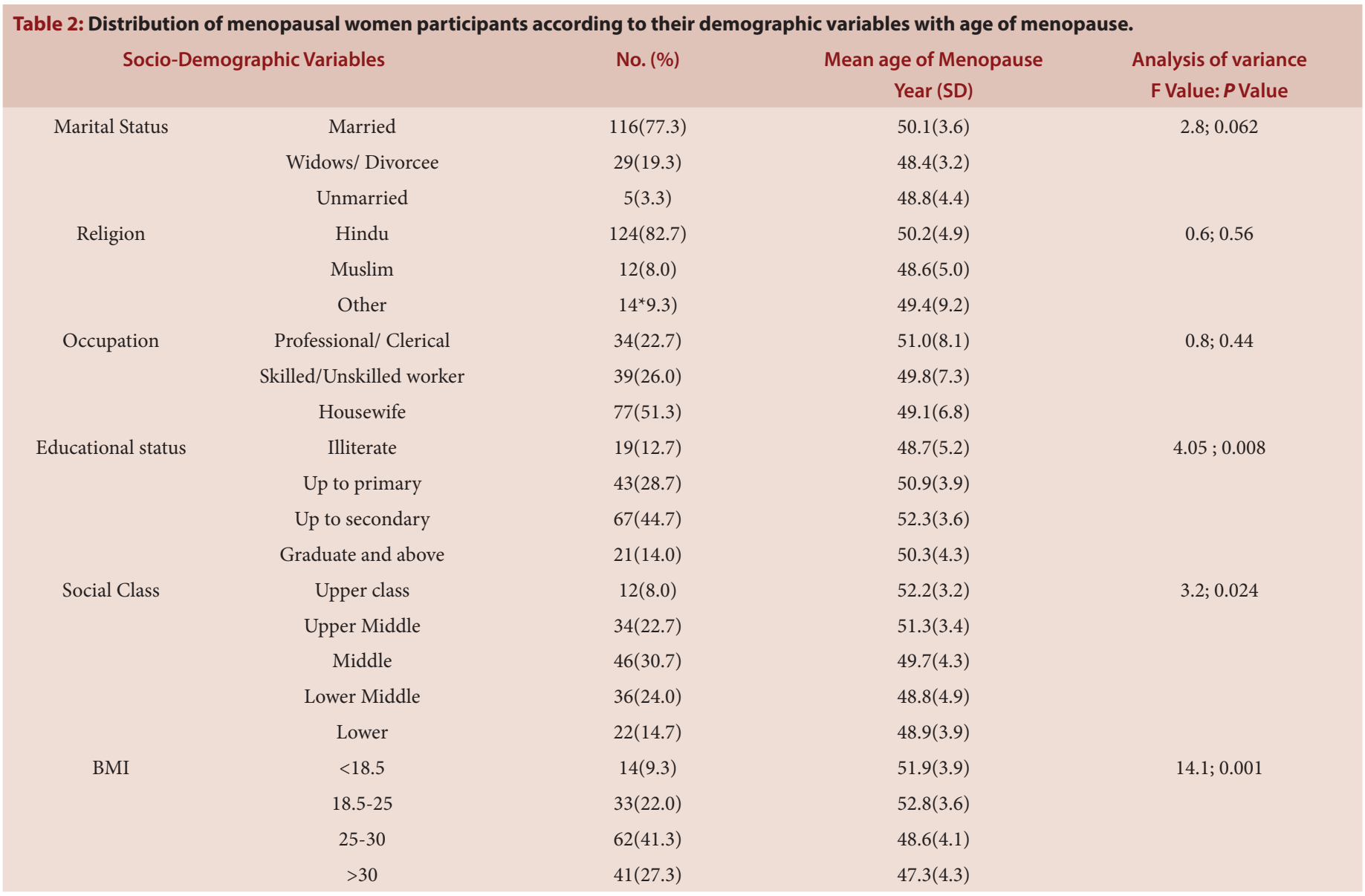

joint and muscular discomfort $106(70.6 \%)$, physical and mental exhaustion $92(61.3 \%)$ and sleeping problems $89(59.3 \%)$. This was followed by anxiety 73(48.6), irritability 68 (45.3\%), symptoms of hot flushes and sweating 58(38.6\%), depressive mood 57 (38.0\%), Pain/Burning sensation in vulva//vagina 52 (34.6\%), dryness of vagina 49 (32.6\%), incontinence/Frequency of urine 41 (27.30 and heart discomfort/palpitation $35(23.3 \%)$. A high significance (ANOVA=9.89, $p=0.000$ ) level indicates higher menopausal symptoms among participants who belongs to perimenopausal and postmenopausal then the premenopausal. Observation on ANOVA confirms by Tukey HSD Post-hoc test that symptoms were more prominent and significantly in to perimenopausal and postmenopausal then the premenopausal state ( $p=0.003$ and 0.0462 respectively), while there was no significant difference in menopausal symptoms in between perimenopausal and post menopausal women.

The Table 4 shows that the mean score was 4.2 in all menopausal women. Somatic symptoms score 134 (46.5\%) and psychological symptoms scores 149 (51.4\%) were the leading score in the perimenopausal women while Uro-genital symptoms score $74(42.5 \%)$ was more in post menopausal women. Average mean total symptoms score was 5.9 in perimenopausal women and 4.8 in post menopausal women reflecting more severity during perimenopausal duration and it was found significant difference in comparison to premenopausal women who have much less mean score (3.4). It was also confirmed by analysis of variance test in between all three groups.

Table 5 in multivariate analysis, elaborated Coping activities emerged as significant predictors for low menopausal symptoms. The odds of high menopausal symptoms among women who are not involved in exercising/ self calming skill by 4.3 with high mean score $5.3 \pm 1.9$ in comparison to women were practicing self calming skill have less mean score $4.3 \pm 1.5$. Similarly the odds high menopausal symptoms among women who are not aware about their diet and weight controlled by 2.0 with mean score $5.2 \pm 2.0$ vs. $4.5 \pm 1.6$ who were aware. The risk of high menopausal symptoms 


\begin{tabular}{|c|c|c|c|c|}
\hline Subscale (menopausal symptoms) & All $(n=150)$ & Premenopausal $(n=34)$ & Perimenopausal $(\boldsymbol{n}=59)$ & Postmenopausal $(n=57)$ \\
\hline \multicolumn{5}{|c|}{ Somatic } \\
\hline 1. Hot flushes, sweating & $58^{\star}(38.6)$ & $13(38.2)$ & $29(49.1)$ & $16(28.1)$ \\
\hline 3. Sleeping problems & $89(59.3)$ & $12(35.3)$ & $45(76.3)$ & $32(56.1)$ \\
\hline 4. Joint and muscular discomfort & $106(70.6)$ & $12(35.3)$ & $45(76.3)$ & $49(85.9)$ \\
\hline 6. Irritability & $68(45.3)$ & $14(35.4)$ & $36(61.1)$ & $18(31.6)$ \\
\hline 7. Anxiety & $73(48.6)$ & $14(41.2)$ & $44(74.6)$ & $15(26.3)$ \\
\hline 8. Physical and mental exhaustion & $92(61.3)$ & $15(44.1)$ & $38(64.4)$ & $39(68.4)$ \\
\hline \multicolumn{5}{|c|}{ Urogenital } \\
\hline 9. Pain/ Burning sensation in vulva/vagina & $52(34.6)$ & $8(23.5)$ & $25(42.3)$ & $19(33.3)$ \\
\hline
\end{tabular}

${ }^{*}$ Many patients had more than one symptoms: hence the total may not match

Analysis of Variance:

$\mathrm{F}$ Value $=9.8950, P$ Value $=0.0004[$ Significant $]$

Tukey HSD Post-hoc Test...

Premenopausal vs. Perimenopausal: $\mathrm{Diff}=49.2000,95 \% \mathrm{CI}=21.9947$ to $76.4053, p=0.0003$

Premenopausal vs. Postmenopausal: $\mathrm{Diff}=27.6000,95 \% \mathrm{CI}=0.3947$ to $54.8053, p=0.0462$

Perimenopausal vs. Postmenopausal: $\mathrm{Diff}=-21.6000,95 \% \mathrm{CI}=-48.8053$ to $5.6053, p=0.1413$

\begin{tabular}{|c|c|c|c|c|c|c|c|}
\hline $\begin{array}{l}\text { Sl. } \\
\text { No }\end{array}$ & $\begin{array}{l}\text { Domains of } \\
\text { Symptoms }\end{array}$ & $\begin{array}{c}\text { No. of } \\
\text { Menopausal } \\
\text { symptoms (12) }\end{array}$ & $\begin{array}{c}\text { Total } n(\%) \\
{[N=150]}\end{array}$ & $\begin{array}{l}\text { Premenopausal } \\
\qquad(n=34)\end{array}$ & Perimenopausal $(n=59)$ & $\begin{array}{l}\text { Postmenopausal } \\
\qquad(n=57)\end{array}$ & $P$ value \\
\hline 1. & $\begin{array}{c}\text { Somatic } \\
\text { (Maximum } \\
\text { Score }=600 \text { ) }\end{array}$ & 4 & $288(48.0)$ & $40(13.9)$ & $134(46.5)$ & $114(39.6)$ & $0.001^{*}$ \\
\hline 2 & $\begin{array}{l}\text { Psychological } \\
\text { (M.Score }=600)\end{array}$ & 4 & $290(48.3)$ & $51(17.6)$ & $149(51.4)$ & $90(31.0)$ & $0.002^{*}$ \\
\hline 3 & $\begin{array}{c}\text { Uro-genital } \\
\text { (M.Score }=600)\end{array}$ & 4 & $170(28.3)$ & $26(15.3)$ & $70(41.2)$ & $74(42.5)$ & $0.019^{*}$ \\
\hline \multicolumn{3}{|c|}{ Total Score } & $748(41.5)$ & $117(15.6)$ & $353(47.2)$ & $278(37.2)$ & \\
\hline \multicolumn{3}{|c|}{ Mean Score (SD) } & 4.2 & 3.4 & 5.9 & 4.8 & \\
\hline
\end{tabular}

* Significant statistically

\begin{tabular}{|c|c|c|c|c|c|c|}
\hline \multicolumn{2}{|c|}{ Coping activities } & No. (\%) & $\begin{array}{c}\text { Menopausal } \\
\text { symptoms present } \\
\text { No (\%) }\end{array}$ & Odd Ratio & $\begin{array}{l}\text { Total average score of } \\
\text { Menopausal symptoms (Max } \\
\text { Score 12) Mean (SD) }\end{array}$ & $P$ value \\
\hline \multirow{2}{*}{\multicolumn{2}{|c|}{$\begin{array}{l}\text { Self-calming skill (Exercise, Yoga, Relaxation } \\
\text { breathing exercise }\end{array}$}} & Yes $(\mathrm{N}=58)$ & $24(41.4)$ & Reference & $4.3(1.5)$ & $0.008^{*}$ \\
\hline & & No $(\mathrm{N}=92)$ & $58(63.0)$ & 2.41 & $5.3(1.9)$ & \\
\hline \multicolumn{2}{|c|}{ Awareness about diet and weight controlled } & Yes $(\mathrm{N}=69)$ & $36(52.2)$ & Reference & $4.5(1.6)$ & $0.02^{*}$ \\
\hline \multirow{3}{*}{$\begin{array}{l}\text { Maintain sense of } \\
\text { achievements }\end{array}$} & & No (108) & $66(61.1)$ & 2.09 & $5.1(2.1)$ & \\
\hline & Maintains social & Yes $(\mathrm{N}=82)$ & $42(51.2)$ & Reference & $4.4(1.4)$ & $0.001^{*}$ \\
\hline & relationships & No $(\mathrm{N}=68)$ & $48(73.8)$ & 2.28 & $5.3(2.0)$ & \\
\hline \multirow{2}{*}{\multicolumn{2}{|c|}{ Medical Treatment }} & Yes $(\mathrm{N}=42)$ & $12(28.6)$ & Reference & $3.9(1.3)$ & \\
\hline & & No $(\mathrm{N}=108)$ & $70(64.8)$ & 4.6 & $5.6(2.8)$ & \\
\hline
\end{tabular}




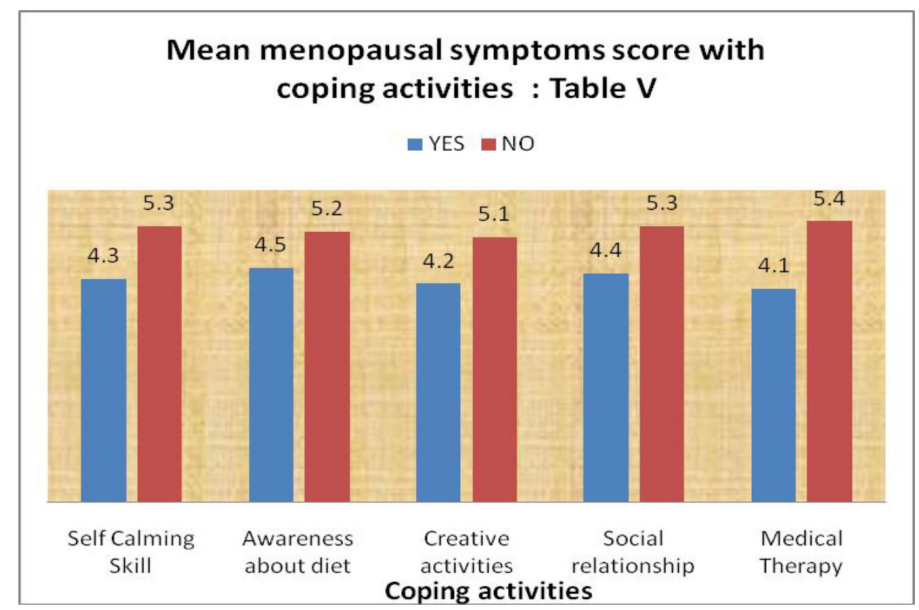

increases among women who were not involved in creative activities by 2.1 with mean score $5.1 \pm$. 2.1 vs indulging $4.2 \pm 1.4$ and who were not maintain social relationship by 2.3 times with significant difference in mean score as $5.3 \pm 2.0$ vs. not maintaining $4.4 \pm 1.4$. Odds ratio found increased 4.6 times with significant high mean score $5.6 \pm 2.8$ in women who are not consulting to physician for their menopausal symptoms in comparison to women were taking some types of medical therapy (Mean score $3.9 \pm 1.3 ; p=0.001$ ).

\section{DISCUSSION}

The mean age at menopause in this study was $49.8 \pm 4.89$ years. Although this is slightly lower than the studies done in Malaysia which reported mean age of menopause $51.28 \pm 2.28$ years and similar to studies done in Peninsular Malaysia which reported mean age of menopause between 49.4 to 51.1 years but slightly higher than studies done in Thailand (48.7 years), Singapore (49.1 years) and other studies on Asian and Caucasian women, our findings still falls between the normal range of menopausal age. ${ }^{13,7,14}$ In other studies done in India and outside India, the mean age of onset of menopause ranged between 44.5 and 51.3 years. ${ }^{13,15,16}$ In the present study, higher mean age of dysmenorrhoea was found among literate women and of higher social class but interestingly dysmenorrhoea symptoms was found early in obese women, which was consistent with the results in the studies. ${ }^{13,17}$ In the present study, the participating women's socio-demographic characteristics were compared with the mean age of dysmenorrhoea. The comparison revealed that the mean age of dysmenorrhoea was higher among the women who were more literate, having higher socio-economic status but interestingly dysmenorrhoea was found early in obese women. A statistically significant difference was observed between their mean age of dysmenorrhoea in terms of education, social status, as well as normal weight maintenance $(p<0.05)$, which was also consistent with the results in the literature. ${ }^{13,17}$ The assessment tool that we used in our study was based on Menopause Rating Scale (MRS) questionnaire. Although These questionnaires is a self-administrated questionnaires, it's used were not only meant to assess the menopausal symptoms but also its severity, however, in our study, modification has to be done on the scaling of the original MRS because we noted that the respondents had difficulties in rating the scales, so to minimize the reporting error, face to face interviewed were used instead of self-administered by the respondents. ${ }^{10,18}$ In this study perimenopausal women were noted to experience more of somatic symptoms when compared to other menopausal group of women and this was also statistical significant. This can be explained by the fact that in these groups of women, estrogen fluctuation during this phase occurs the most, hence they will experience the most somatic symptoms.
Our findings were corresponded to studies conducted among Malaysia*, Australia and other Caucasian women; where as high as $75 \%$ of perimenopausal women experienced bothersome vasomotor symptoms at some point of their transitional period..$^{13,19,20,21}$ In our observations, association was noticed between type of symptoms and menopausal status. Here somatic followed psychological symptoms were seen more among perimenopausal women while urogenital symptoms were more among postmenopausal women. Results were found similar to In other studies, perimenopausal women experienced higher prevalence of somatic and psychological symptoms compared to pre and postmenopausal women. Also these studies found urogenital symptoms to occur more among postmenopausal women.7,13 A study done in Singapore found urogenital symptoms to be more among perimenopausal women and no association between somatic symptoms and menopausal status similar to our findings, ${ }^{22}$ while study done in Thailand found somatic symptoms to be significantly more in postmenopausal group. ${ }^{6}$

From our study, joints and muscular discomfort; physical and mental exhaustions and sleeping problems (Table 3 ) which is from the somatic and psychological subscales were experienced most by perimenopausal followed by postmenopausal women and these was also statistical significant differences when compared to premenopausal women. These findings were also noted to be corresponding to studies conducted abroad. ${ }^{6,13,14,23,24,25}$ The most common symptoms of menopause seen in this study were physical and mental exhaustion and joint and muscle aches, which was similar to the findings of another regional study. ${ }^{26}$ Several studies have reported joint and muscle pains as the commonest menopausal symptom..$^{22,27,28}$ There are also studies which have reported feeling of tiredness and easy fatigability as the commonest symptom of menopause. ${ }^{13,29}$ On the other hand, a study done in Iran reported night sweats, a study done in Malaysia reported hot flushes. ${ }^{30,31}$ It is interesting to note that in our study, as much as $35 \%$ to $44 \%$ of premenopausal women also reported similar symptoms (joint and muscular discomfort, anxiety, depressing mood, irritability, physical and mental exhaustion), this could be explained since most of the somatic or psychological symptoms experienced by these middle age women are not exclusively as a result of changes due to menopause alone, it's could also resulted from other physical, psychological or health related problems which is related to aging in these group of women which can represent as menopausal like symptoms. ${ }^{11,13,18,23}$ Psychosocial problems of menopause assessed in this study were anxiety, depression, irritability and physical and mental exhaustion. Among those who complained of psychological symptoms, $61 \%$ reported physical and mental exhaustion, $48 \%$ reported anxiety, 45\% depression and 38\% depression (Table 3). Similarly Psychological problems during menopause are well documented in literature (Rahman SA et al. 2010, ${ }^{13}$ Hardy and Kuh 2002, ${ }^{31}$ Mishra and Kuh 2006. $)^{32}$ In urogential subscale (Pain/Burning sensation in vulva/vagina, burning micturition, incontinence /Frequency of urine and, vaginal dryness), from our study the frequency of these symptoms were experienced more by postmenopausal group of women and it was also significant statistically when compared to other menopausal status and similar finding were also documented from other studies. ${ }^{6,12,23,24}$ The frequency of urogenital problems in this study was $41.5 \%$ and was very similar to the proportion reported in a study done in Malaysia. ${ }^{14}$ In the study done in Nigeria, age of the respondent and menopausal status was found to be significantly associated with scores of somatic and urogenital subscales. ${ }^{33}$ The above mentioned study also found a significant association between occupational status of participants with psychological subscale which was not observed in our study. In our study it was noted that somatic and psychological symptoms were experienced mainly by perimenopausal women (46.5\% and 51.4\%) compared to the postmenopausal or premenopausal women. However, in the urogenital symptoms, the postmenopausal women were reported to suffer the more (42.5\%) compared 
to the other two groups and similar findings were reported from other studies. ${ }^{5,6,7,12,23}$ The mean number of symptoms reported by participants in our study was 4.2 when compared to 7.6 reported in a study done in Malaysia. A study done in Kannur found mean number of symptoms to be 4.9 , which was lower than our findings. ${ }^{1}$ Analysis informs a significant association in menopausal symptoms with nature of exercise (Self calming skill), Awareness about diet, having creative activities and sense of social relationship and awareness regarding some type of medical remedy. Those participants, who exercise at home, aware about diet, maintain sense of achievement and taking some medical advice reported fewer psychological problems of menopause. Study by Some author also suggested that exercise has been found to be beneficial to combat both physical and psychological problems of menopause (Meeta et al. 2013;34 Teoman, et al. 2004). ${ }^{35}$ However, Kamil et al..$^{36}$ did not determine a significant relationship between menopausal women's doing regular physical exercise and their quality of life. Asbury EA et al. (2006) ${ }^{37}$ conducted a study on, The importance of continued exercise participation in quality of life and psychological well-being in previously inactive postmenopausal women, suggest that Healthy postmenopausal women gain significant psychological benefit from moderate-intensity exercise. Maintaining a healthy diet is another way for post menopausal women to remain problem free. Similarly such study was conducted by Baksu B et al. ${ }^{38}$ on', Effect on hormonal therapy on postmenopausal women proved that hormonal therapy helps in reducing psychological symptoms of postmenopausal women.

\section{CONCLUSION}

The analysis of different cases of the present study shows that the menopausal women are not aware of the fact that for many of their psychosocial and physical problems, it is menopause that is responsible, quite often they were attributing these to their personal calamities. With the increasing life expectancy women spends almost a third of her life in menopause. ${ }^{39}$ Health issues of postmenopausal women therefore would pose a significant challenge to public health also considering the fact that there hasn't been a specific health program for such women in the country. The current geriatric health care services is largely based on the general health problems of the elderly and not directed specifically to the postmenopausal health problems. Now time has come for India to develop and start educational campaign elaborating "How to coping the symptoms of menopause among women" at all level of community.

\section{Limitation}

There are several limitations of this study. Although attempts were made to ensure that the study population was as representative as possible of the general population of the North India, nevertheless it has to be stated owing to the sampling technique used this might not be entirely possible. Another limitation was, as this was a cross sectional study, it does not exclude other confounding effects of the natural aging process that may influence experience of symptoms. A final limitation of this study is lack of information on regularity of menstruation. Some subjects could have been misclassified into the incorrect menopause status group.

\section{CONFLICT OF INTEREST}

The authors declare no conflict of interest.

\section{REFERENCES}

1. Borker SA, Venugopalan PP, Bhat SN. Study of menopausal symptoms and perceptions about menopause among women at a rural community in Kerala. J Midlife Health. 2013;4(3):182-7.

2. The Nurse Practitioner: Clinical Case Report: Anxiety Attacks following Surgical Menopause. May 2006;31(5):44-9.
3. Nutan P, Mahadeo S. Psychological Problems and Coping Strategies Adopted By Post Menopausal Women. International Journal of Science and Research. 2014;3(2):293-300.

4. Williams RE, Levine KB, Kalilani L, Lewis J, Clark RV. Menopause-specific questionnaire assessment in US population-based study shows negative impact on health-related quality of life. Maturitas. 2009;62(2):153-9.

5. Lu J, Liu J, Eden J. The experience of menopausal symptoms by Arabic women in Sydney. Climacteric. 2007;10(1):72-7.

6. Peeyananjarassri K, Cheewadhanaraks S, Hubbard M, Zoa MR, Manocha R, Eden J. Menopausal Symptoms in a hospital-based sample of women in southern Thailand. Climacteric. 2006;9(1):23-9.

7. Chedraui P, Blümel JE, Baron G, et al. Impaired quality of life among middle aged women: A multicentre Latin American study. Maturitas. 2008;61(4):323-9.

8. Mary RT, Catherine Booth-LaForce, Rebecca C. et al. Participant Perspectives on a Yoga Intervention for Menopausal Symptoms. Journal of Evidence Based Integrative Medicine. 2008;13(3):171-81.

9. Heinemann LA, Potthoff P, Schneider HP. International version of the menopause rating scale (MRS). Health and Quality Life Outcomes. 2003;1(1):28.

10. World Health Organisation (WHO).Research on the menopause in the 1990s: report of a WHO scientific group.

11. Siobán DH, Margery G, Janet EH, et al. Executive summary of the Stages of Reproductive Aging Workshop + 10: addressing the unfinished agenda of staging reproductive aging. The Journal of Clinical Endocrinology and Metabolism. 2012;97(4):1159-68.

12. Agarwal A. Social classification: The need to update in the present scenario. Indian J Community Med. 2008;33(1):50-1.

13. Rahman SA, Zainudin SR, Mun VL. Assessment of menopausal symptoms using modified Menopause Rating Scale (MRS) among middle age women in Kuching, Sarawak, Malaysia. Asia Pac Farm Med. 2010;9:5

14. Boulet MJ, Oddens BJ, Lehert P, Verme HM, Visser AP. Climacteric and menopause in seven South-east Asian countries. Maturitas 1994;19(3):157-76.

15. Jahan FS, Abdul RB, Shah RB, Nor AB, Sharifah NB, Siti AB. Age at menopause and menopausal symptoms among Malaysian women who were referred to a health clinic in Malaysia. Shiraz E-Med J. 2006;7:3

16. Christian DS, Kathad M, Bhavsar B. A clinico-epidemiological study on health problems of post-menopausal women in rural area of Vadodara District, Gujarat. Natl J Med Res. 2012;2:478-80.

17. Schneider HP. The quality of life in the postmenopausal woman. Best Pract Res Clin Obstet Gynaecol. 2002;16(3):395-409.

18. Green JG. Construction a standard climacteric scale. Maturitas. 1998;29:19-24.

19. Takeshi A. First Consensus Meeting on Menopause in the East Asian Region: Demography of the menopause and pattern of climacteric symptoms in the East Asian region. Geneva Foundation for Medical Education and Research 2003.

20. Dennerstein L, Duddley EC, Hopper JL, Guthrie JR, Burger HG. A perspective population-based study of menopausal symptoms. Obstet Gynecol. 2000;96(3):351-8

21. Lam PM, Leung TN, Haines $C$, Haines TK. Climacteric symptoms and knowledge about hormone replacement therapy among Hong Kong Chinese women aged 40-60 years. Maturitas. 2003;45(2):99-107.

22. Chim H, Tan BH, Ang CC, Chew EM, Chong YS, Saw SM. The prevalence of menopausal symptoms in a community in Singapore. Maturitas. 2002;41(4):275-82.

23. Porter M, Penny GC, Russell D, Russell E, Templeton A. A population based survey of women's experience of the menopause. BJOG: An International Journal of Obstetrics and Gynaecology. 1996;103(10):1025-8.

24. Dhillon HK, Singh HJ, Rashidah S, Abdul MH, Nik Mohd NM. Prevalence of menopausal symptoms in women in Kelantan. Malaysia. Maturitas. 2006;54(3):213-21.

25. Park YJ, Kim HS, Chang SO, Kang HC, Chun SH. Sexuality and related factors of postmenopausal Korean women. Taehan Kanko Hakhoe Chi. 2003;33(4):457-63.

26. Bairy L, Adiga S, Bhat $P$, Bhat R. Prevalence of menopausal symptoms and quality of life after menopause in women from South India. Aust N Z J Obstet Gynaecol. 2009;49(4):106-9.

27. Rahman S, Salehin F, lqbal A. Menopausal symptoms assessment among middle age women in Kushtia, Bangladesh. BMC Res Notes. 2011;4(1):188.

28. Nisar N, Sohoo NA. Frequency of menopausal symptoms and their impact on the quality of life of women: A hospital based survey. J Pak Med Assoc. 2009;59(11):752-6.

29. Mahajan N, Aggarwal M, Bagga A. Health issues of menopausal women in North India. J Midlife Health. 2012;3(2):84-7.

30. Ashrafi M, Ashtiani SK, Malekzadeh F, Amirchaghmaghi E, Kashfi F, Eshrati B. Factors associated with age at natural menopause in Iranian women living in Tehran. Int J Gynaecol Obstet. 2008;102(2):175-6.

31. Hardy R, Kuh D. Change in psychological and vasomotor symptoms reporting during the menopause. Social Science and Medicine. 2002;55(11);1975-88.

32. Mishra G, Kuh D. Perceived change in quality of life during the menopause. Social Science and Medicine. 2006;62(1);93-102. 
33. Olaolorun FM, Lawoyin TO. Experience of menopausal symptoms by women in an urban community in Ibadan, Nigeria. Menopause. 2009;16(4):822-30.

34. Meeta LD, Agarwal N, Vaze N, Shah R, Malik S. Clinical practice guidelines on menopause: An executive summary and recommendations. J Midlife Health. 2013;4(2):77-106.

35. Teoman, Nursen, Edeer, Ayse, Acar, Berrin. The effect of exercise on physical fitness and quality of life in Postmenopausal women. Maturitas. 2004;47(1):71-7.

36. Kamile A, Emel E, Rabia A, et al. Sexual Quality of Life in Women during the Climacteric Period. International Journal of Caring Sciences.
2016;1(9):296-7.

37. Asbury EA, Chandrruangphen P, Collins P. The importance of continued exercise participation in quality of life and psychological well-being in previously inactive postmenopausal women: a pilot, study. Menopause. 2006;13(4):561-7.

38. Baksu B, Baksu A, Göker N, Citak S. Do different delivery systems of hormone therapy have different effects on psychological symptoms in surgically menopausal women? A randomized controlled trial. Maturitas. 2009;62(2):140-5.

39. Vaze N, Joshi S. Yoga and menopausal transition. J Midlife Health. 2010;1(2):56-8.

Cite this article : Agarwal AK, Kiron N, Gupta R, Sengar A. A Cross Sectional Study for Assessment of Menopausal Symptoms and Coping Strategies among the Women of 40-60 Years Age Group Attending Outpatient Clinic of Gynaecology. Int J Med Public Health. 2019;9(1):13-9. 